\title{
Study of In-Flight and Impact Dynamics of Nonspherical Particles from HVOF Guns
}

\author{
S. Kamnis and S. Gu
}

(Submitted April 16, 2009; in revised form July 15, 2009)

\begin{abstract}
High velocity oxygen fuel thermal spray has been widely used to deposit hard composite materials such as WC-Co powders for wear-resistant applications. Unlike gas atomized spherical powders, WC-CO powders form a more complex geometry. The knowledge gained from the existing spherical powders on process control and optimization may not be directly applicable to WC-Co coatings. This paper is the first to directly examine nonspherical particle in-flight dynamics and the impingement process on substrate using computational methods. Two sets of computational models are developed. First, the in-flight particles are simulated in the CFD-based combusting gas flow. The particle information prior to impact is extracted from the CFD results and implemented in a FEA model to dynamically track the impingement of particles on substrate. The morphology of particles is examined extensively including both spherical and nonspherical powders to establish the critical particle impact parameters needed for adequate bonding.
\end{abstract}

Keywords CFD, FEA, HVOF, impingement, nonspherical, WC-Co

\section{Introduction}

High velocity oxygen fuel (HVOF) thermal spraying has been applied successfully in producing coatings with higher density, superior bond strengths, and less decarburization due to its unique output of high particle velocities and relatively low particle temperatures. In the HVOF process, oxygen and fuel are mixed and burnt in a combustion chamber at high flow rates (up to $1000 \mathrm{~L} / \mathrm{min}$ ) and pressures (up to 12 bar) in order to produce a hot high-speed gas jet. Powder particles, normally in the size range 5-65 $\mu \mathrm{m}$, are injected into the gas jet where they are heated and accelerated toward the substrate. On impact the particles form lenticular splats, which adhere well to the substrate and to one another. The HVOF gun is scanned cross the substrate to build up the required coating thickness in a number of passes.

This article is an invited paper selected from presentations at the 2009 International Thermal Spray Conference and has been expanded from the original presentation. It is simultaneously published in Expanding Thermal Spray Performance to New Markets and Applications: Proceedings of the 2009 International Thermal Spray Conference, Las Vegas, Nevada, USA, May 4-7, 2009, Basil R. Marple, Margaret M. Hyland, Yuk-Chiu Lau, Chang-Jiu Li, Rogerio S. Lima, and Ghislain Montavon, Ed., ASM International, Materials Park, OH, 2009.

S. Kamnis and S. Gu, School of Engineering Science, University of Southampton Highfield, Southampton SO17 1BJ, UK. Contact e-mail: s.gu@soton.ac.uk.
Computational fluid dynamic (CFD) models have been developed to study the in-flight particle behavior during thermal spraying and the Euler-Lagrange approach has long been used for the modeling of spherical particle-gas interaction in various HVOF thermal spray systems, and the progress of particle modeling can be found in Ref 1-8. The most relevant work for WC-Co particle dynamics has been carried out by Li and coworkers (Ref 9-12) who examined the in-flight particle behavior in a gas fuelled Diamond Jet hybrid HVOF system.

Powder morphology varies according to the technology of powder production. Hardmetals such as WC-Co powders are made from mechanical milling and are not normally spherical. As a class of hard composite materials of great technological importance, WC-Co powder cemented carbides are widely used for protective coatings in a large variety of applications such as mining, turning, cutting, and milling, where abrasion, erosion, and other forms of wear exist $(\operatorname{Ref} 7,13)$. There is a lack of good understanding of the effect of powder morphology on particle dynamics and subsequent influence on the quality of coating.

The impingement and deformation of thermally sprayed particles has been investigated in $2 \mathrm{D}$ and $3 \mathrm{D}$ using CFD (Ref 14-16) and FEA (Ref 17) methods. These studies all focus on the deformation of spherical particles. The purpose of this paper is to study the nonspherical powder spray from HVOF guns. It composes of two parts of modeling work. First, a CFD model is developed to examine the motion and heat transfer history of the in-flight particles and their reaction to particle parameters such as size and shape. The simulation results show that the particles are mainly in solid state prior to impact for a typical stand-off distance of $0.32 \mathrm{~m}$. Based on the input data from the CFD model, a particle impingement model is developed using finite element analysis (FEA) 
method. The FEA model is used to examine the bonding mechanism between particle and substrate and to establish the critical impact parameters for high quality coating.

\section{Model Development}

\subsection{CFD Model}

A schematic representation of the HVOF gun is shown in Fig. 1. The mixture of fuel and oxygen stream is injected into a water-cooled combustion chamber, where the gases burn and the combustion products are accelerated down the convergent divergent nozzle and long parallel-sized barrel. Powder particles are injected into the barrel through two holes that have a tapered angle located in front of the barrel. The particle laden by the gas

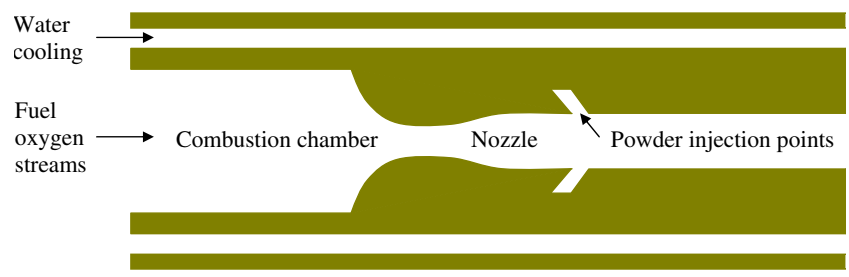

Fig. 1 Schematic of HVOF thermal spray gun mixture exits the gun at a high temperature and a high velocity toward the substrate to be coated.

Full 3D simulations are performed in the commercially available finite volume CFD code Fluent 6.3. The computational geometry for the gun and external domain is shown in Fig. 2. Details of the grid structure and boundary conditions have been described in Ref 18-21 and hence only a brief description is given below. A structured grid is used and fine meshes are employed to sensitive areas such as nozzle entrance/exit, barrel exit, and free-jet centerline where high gradients are expected so that great accuracy is required in order to capture the compressibility effects, and a second-order discretization scheme is applied to model the steady state continuum. Kerosene is the most widely used fuel for HVOF thermal spraying and is selected for the current gas flow simulation. The modeling of turbulent and chemical reaction flow has been described in Ref 18 and will not be repeated here. The process parameters employed in numerical simulations are $3.51 \mathrm{~g} / \mathrm{s}$ for kerosene and $12.9 \mathrm{~g} / \mathrm{s}$ for oxygen. The computation of particle dynamics is achieved by coupling with the Eulerian gas flow. The popular hard materials WC-Co powders are selected in this study with thermophysical properties shown in Table 1 . The powder feeding rate is $100 \mathrm{~g} / \mathrm{min}$.

The WC-Co composite particle is considered as a single entity, with a single set of physical properties. In practice,

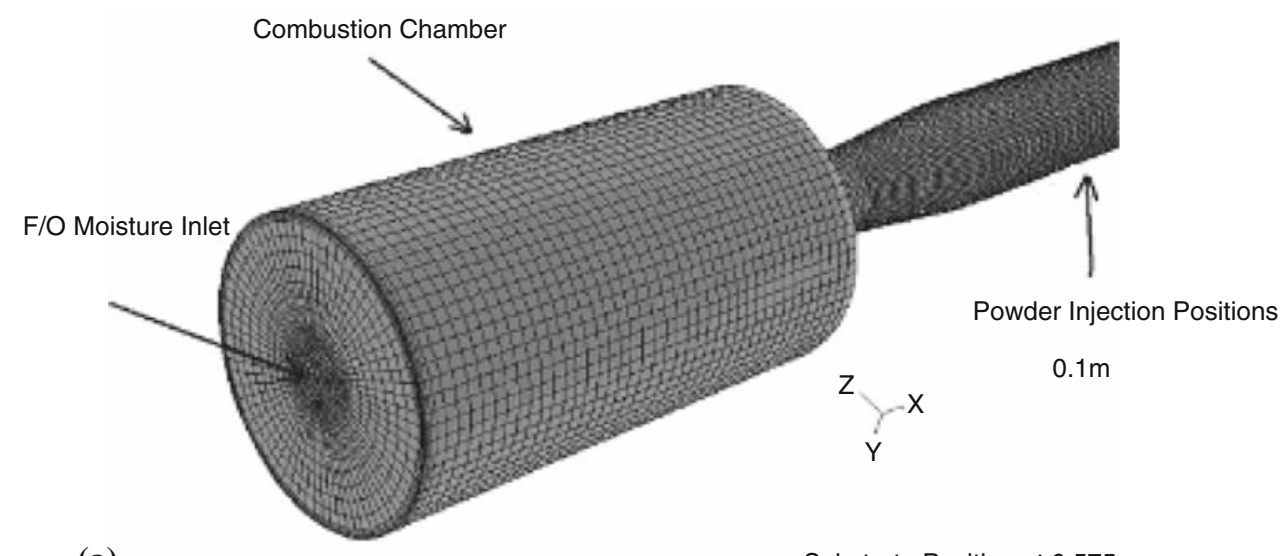

(a)

Substrate Position at $0.575 \mathrm{~m}$

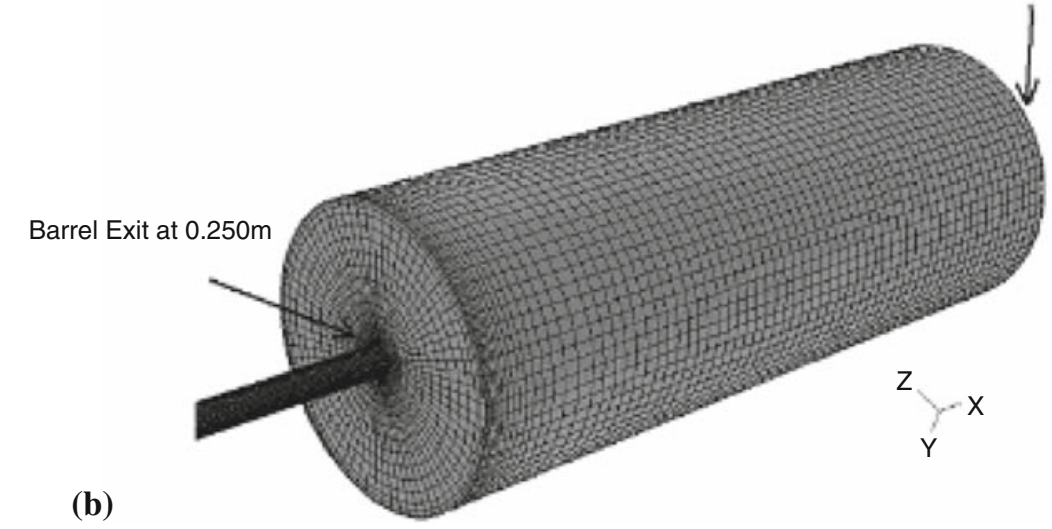

Fig. 2 Computational domain: (a) combustion chamber and front of barrel; (b) external domain 
Table 1 Thermophysical properties for WC-17Co

Density $\left(\rho_{\mathrm{p}}\right), \mathrm{kg} / \mathrm{m}^{3}$

Solidus temperature $\left(T_{\mathrm{S}}\right), \mathrm{K}$

Liquidus temperature $\left(T_{\mathrm{L}}\right), \mathrm{K}$

Primary element melting point $\left(T_{\mathrm{k}}\right), \mathrm{K}$

Partition coefficient, $k_{\mathrm{c}}$

Specific heat $\left(C_{\mathrm{p}}\right), \mathrm{J} / \mathrm{kg} \mathrm{K}$

Latent heat $\left(H_{\mathrm{sf}}\right), \mathrm{J} / \mathrm{kg}$

Thermal conductivity $(k), \mathrm{W} / \mathrm{m} \mathrm{K}$

Young's modulus, GPa

Poison's ratio

Shear Strength, $\mathrm{MPa}$

14,000
1,580
1,640
1,768
0.3
295
420,000
$T<1000 \mathrm{~K}, 25$
$1000<T<1528,15$
$1768<T, 10$
500
0.27
95

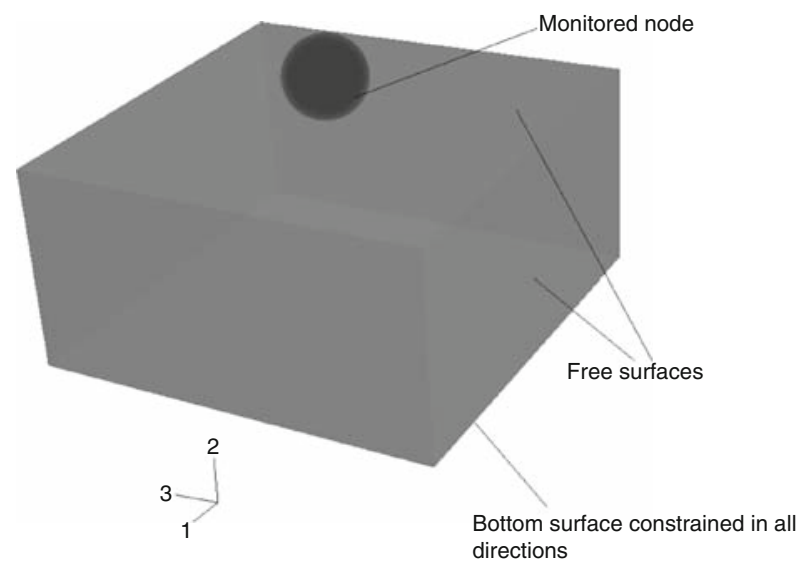

Fig. 3 Computational domain for 3D finite element model

the Co is heated and melted, and then cooled and solidified, which binds the WC onto the substrate. However, temperatures in HVOF thermal spraying are not high enough to melt the tungsten carbide, and therefore the melting point for the primary material, cobalt, is applied in modeling particle heating for both the CFD analysis and the FEA analysis, which is outlined below.

\subsection{FEA Model}

The solid impact dynamics are analysed by using the finite element commercial solver ABAQUS/Explicit. The model developed has been detailed in Ref 16 , and only a brief description is given here. The impingement process of solid particle on substrate is constructed in a 3D domain shown in Fig. 3. The substrate dimension is given to be five times larger than the particle diameter to avoid possible effects on the particle-substrate deforming zones from the boundary nodes. The substrate bottom face is constrained in all directions, while the other faces are set as free. Reports on grid sensitivity have shown that the mesh size can play a dominant role on the material heating and consequently to shear flow localization (Ref 22). For this reason, very fine meshes are employed for both particle and substrate. For instance, $40 \mu \mathrm{m}$ spherical particle had a mesh size of $0.5 \mu \mathrm{m}$ corresponding to approximately
Table 2 Shape factors of particles used in the study

\begin{tabular}{llllll}
\hline Shape factor & Particle shape & \\
\hline $\mathrm{SF}$ & & \\
\hline
\end{tabular}

700,000 4-node linear tetrahedron elements. The velocity and temperature of spray particles prior to impact on the substrate are taken from the CFD in-flight particle model according to the particle size and shape. The monitor node is selected on the surface of the impacting particle at a location which intensive plastic deformation is expected.

\section{Results and Discussions}

A selection of particle geometries are used in this study as shown in Table 2. A shape factor (SF) is used to describe the degree of sphericity. SF is the ratio of the actual surface area of the nonspherical particle to the surface area of the sphere of the same volume as the nonspherical particle. Hence, a circle has a SF of 1 , and the SF decreases as the corner of object become sharper.

\subsection{In-Flight Particle Dynamics}

3.1.1 Particle Morphology Influence on Trajectory. The results in Fig. 4 illustrate the particle trajectories during the simulated spray process. The particles are injected into the HVOF gun radially by a carrier gas and join the high-speed gas jet, which travels in an axial direction. In general, smaller particles are easily carried away by the gas flow and their motion in radial direction is less pronounced. Whereas large particles have greater inertia and therefore maintain their motion in a radial direction, traveling substantial distances across the center of the gun. However, the extent of spreading for nonspherical particles is reduced substantially. The drag exerted on nonspherical particles from the axial gas flow is larger than spherical particles. Therefore, the nonspherical particles have high axial velocity, less dwell (in-flight) time, and reduced traveling distance in radial direction.

3.1.2 Particle Morphology Influence on Velocity. Figure 5 reveals that the increase of sharpness from SF 1 to 0.8 increases the velocity profile for the same size $60 \mu \mathrm{m}$ particles due to an increased drag force. The drag coefficient varies with respect to the SF, and the equations can be found in Ref 23 which also gives a detailed discussion on the influence of SF on the particle drag force. A brief explanation for the increased drag force for nonspherical particles is given here. The change in friction drag is likely to be limited compared to the change in pressure drag. The increase of negative pressure gradient on a nonspherical particle surface is related to the early boundary layer separation of the flow from the object's surface. The 


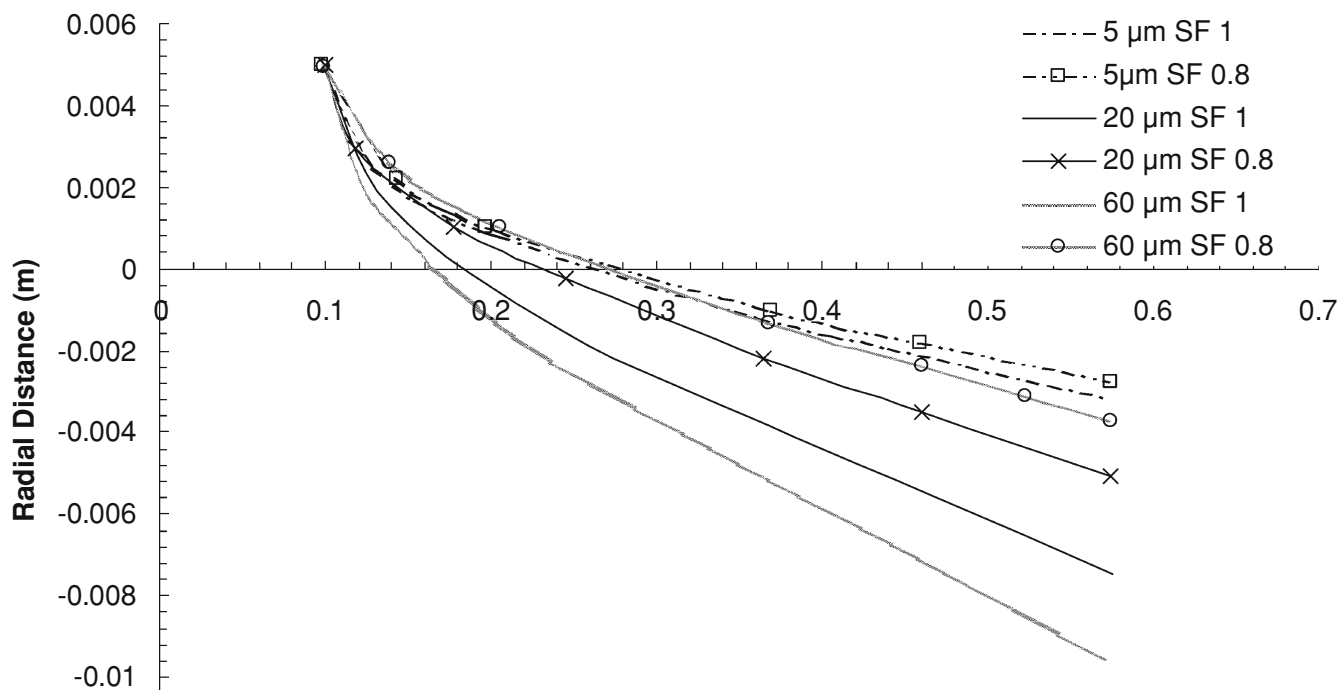

$-0.012$

Axial Distance (m)

Fig. 4 Particle trajectories for different size particles

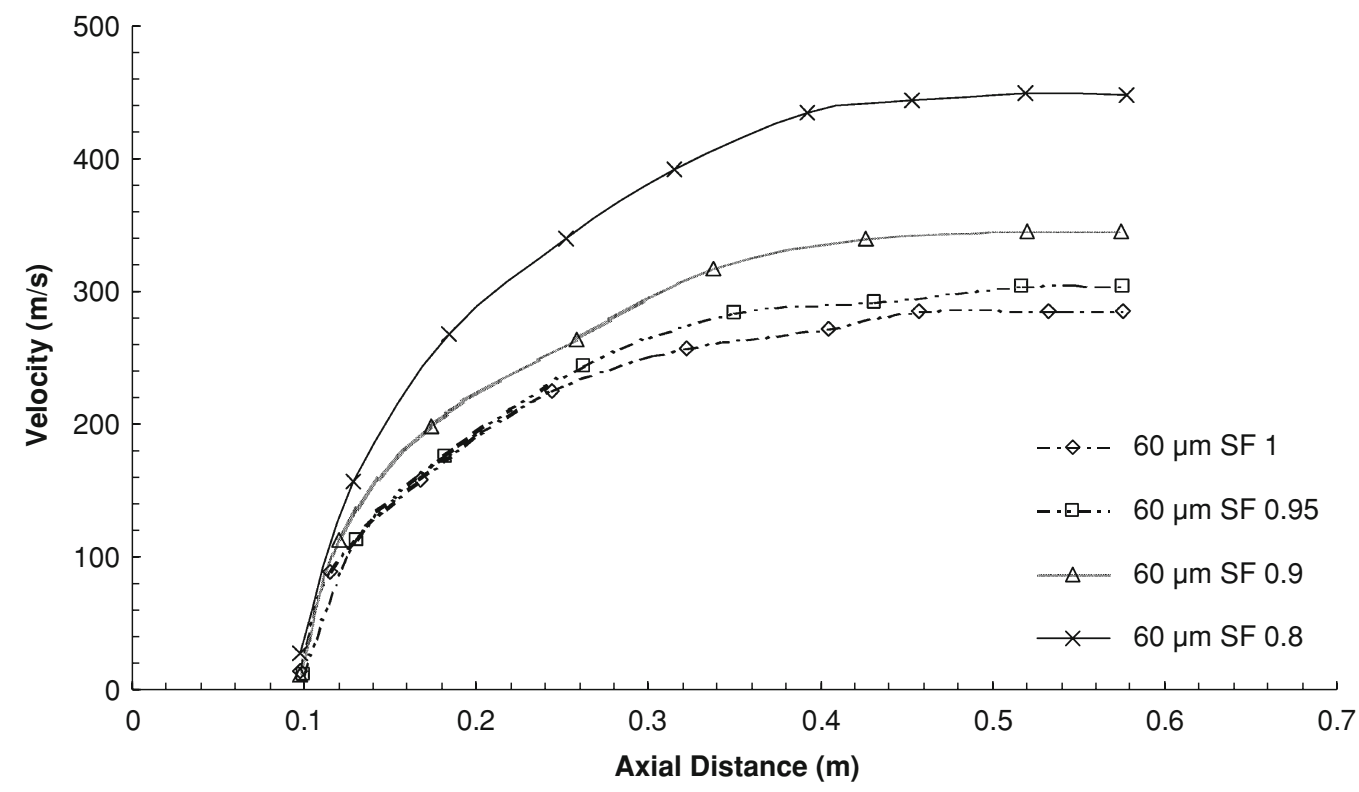

Fig. 5 Velocity evolutions for different shape $60 \mu \mathrm{m}$ particles

more aerodynamic and smooth surface of a spherical particle allows for a boundary layer to remain attached on the surface for longer, which reduces the negative pressure gradient. The higher drag force for the nonspherical particles enables the carrier gas to accelerate the particles to a higher velocity. Such correlation between sphericity and drag force for the in-flight particle dynamics has been confirmed with experimental observation in Ref 24.

The velocity profiles for different size particles are shown in Fig. 6. The results clearly demonstrate that the smaller particles are accelerated more throughout the computational domain. When the particle velocity is higher than the gas velocity, as the gas jet decays outside the gun, the drag force on the particle then changes direction and becomes a resistance to the particle motion. The velocity of the particle is then decreased. The smaller the particle size, the more easily it is to be accelerated and decelerated. A larger particle, on the other hand, is more difficult to be accelerated and has greater ability to maintain its velocity during the deceleration stage, because of its larger inertia. The velocity dependence on particle size is more clearly demonstrated in Fig. 7 which shows the correlation between particle impact velocity and particle size.

By comparing the velocities of 5 and $60 \mu \mathrm{m}$ particles at SF 1 and 0.8 in Fig. 6, it is clear that the improvement of velocity profiles is more substantial for large nonspherical 


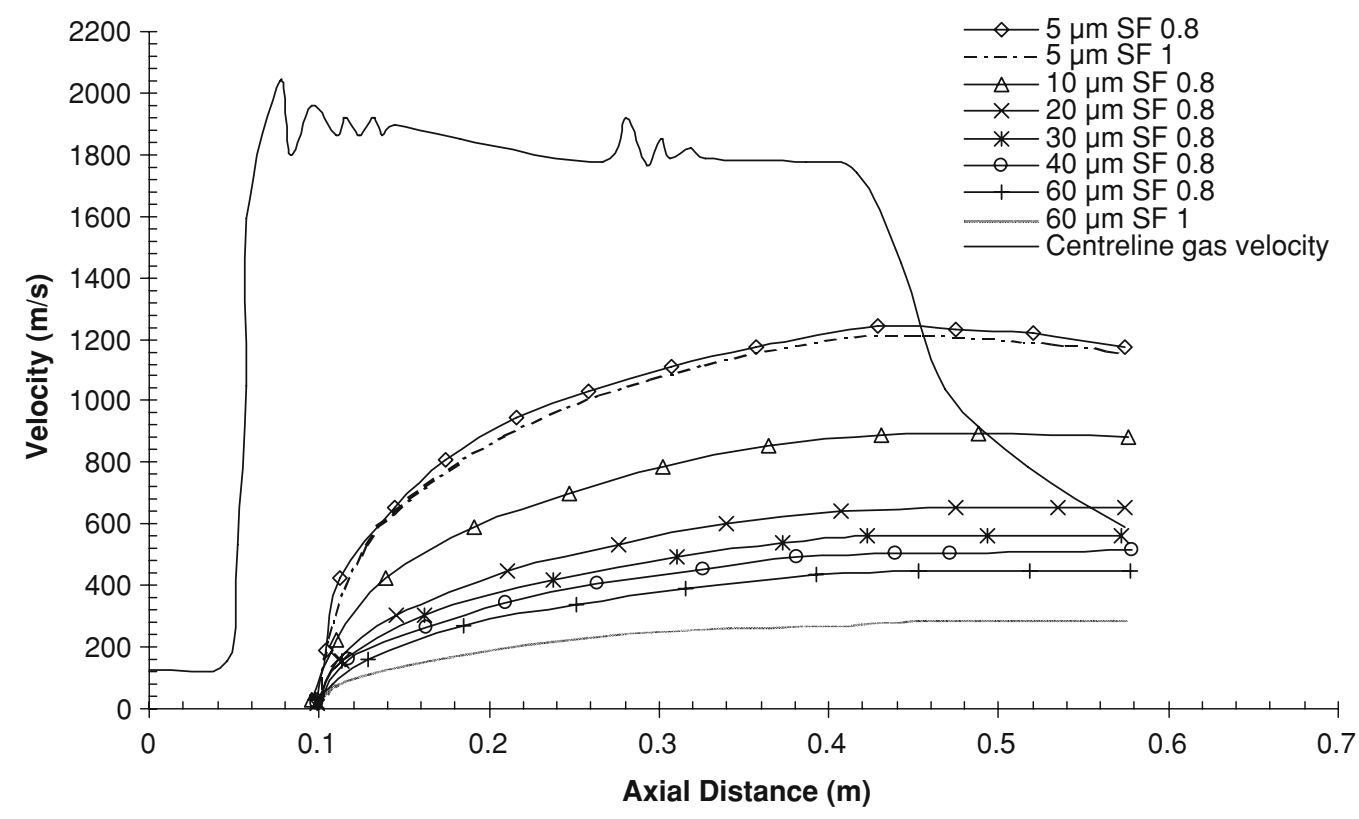

Fig. 6 Velocity evolutions for different size particles

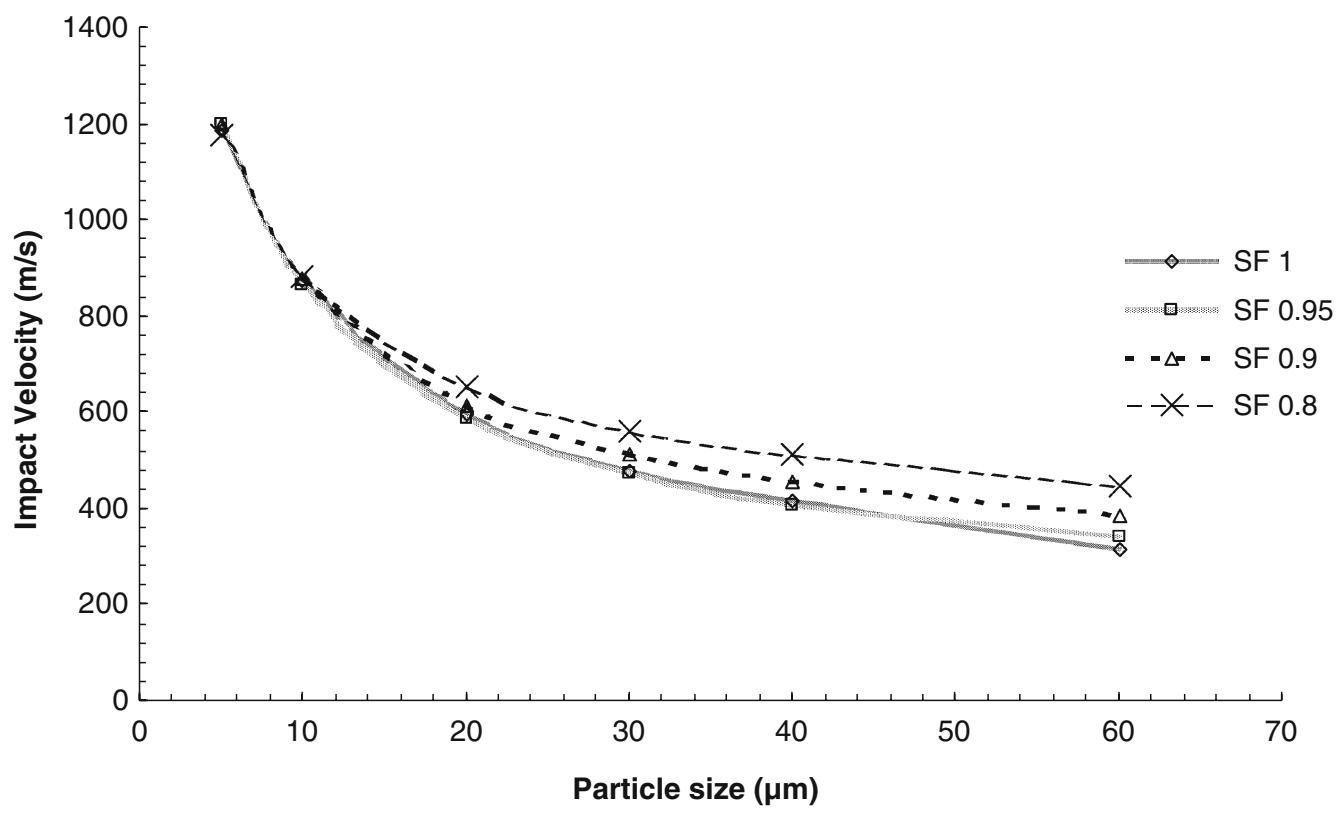

Fig. 7 Particle velocities at impact

particles. It is known that the drag force is positively related to the ratio of particle volume to projected area where the drag force acts on. The larger the particle, the higher the ratio is, therefore more drag force is found for large particles. This combination of high drag coefficient for nonspherical particles and increased particle volume-to-project area ratio for large particle acts favorably to increase the velocity profiles of large nonspherical particles.

3.1.3 Particle Morphology Influence on Temperature. The temperature profiles for different shape $60 \mu \mathrm{m}$ particles are illustrated in Fig. 8. The decline of temperature is evident as the sharpness of the particle increases. It is known that the temperature of the particle is directly related to the dwell time which allows the particle to be heated by the hot gas flow during the in-flight period. The increase of velocity for nonspherical powder as shown in Fig. 5 reduces the dwell time of nonspherical particles, results in the lower temperature profiles.

The temperature evolutions of different-sized particles are shown in Fig. 9. A quantitative display of particle impact temperature is shown in Fig. 10. The results show that the temperature of the particle increases sharply in 


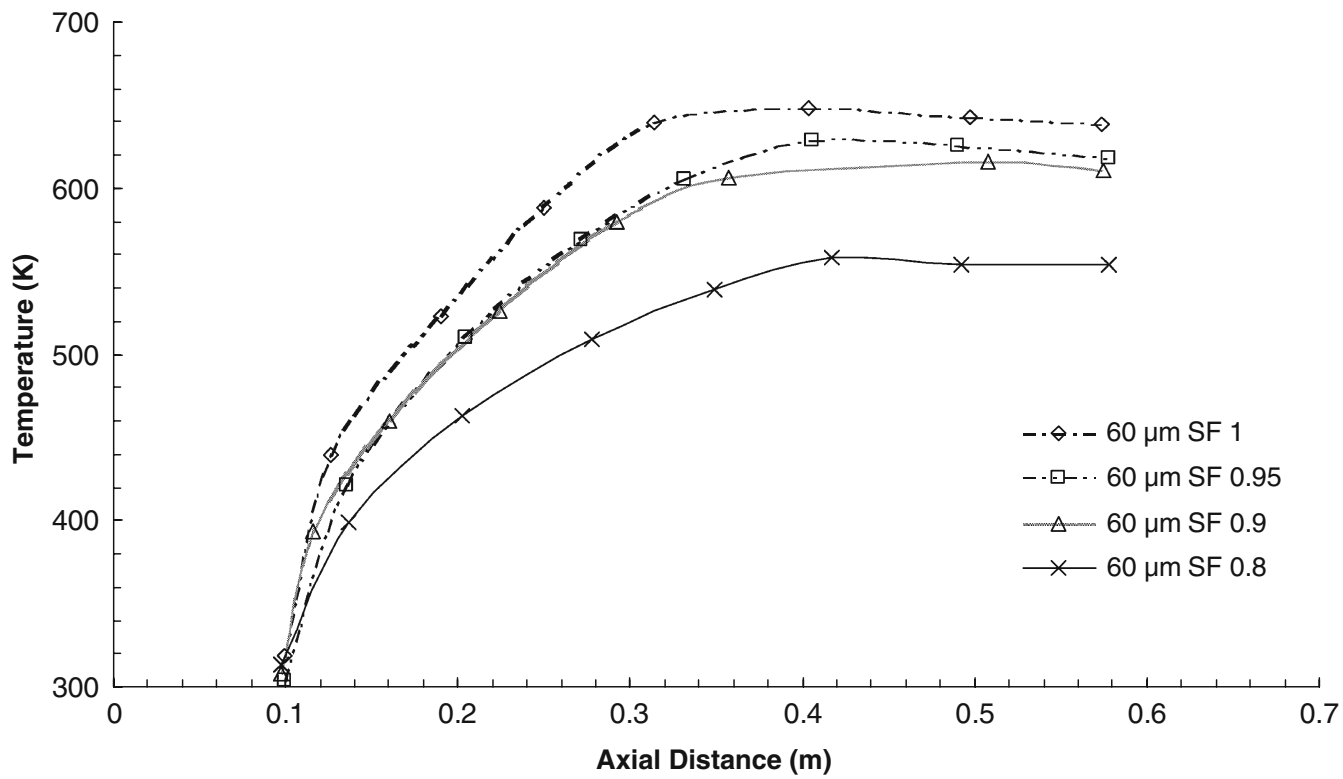

Fig. 8 Temperature evolutions for different shape $60 \mu \mathrm{m}$ particles

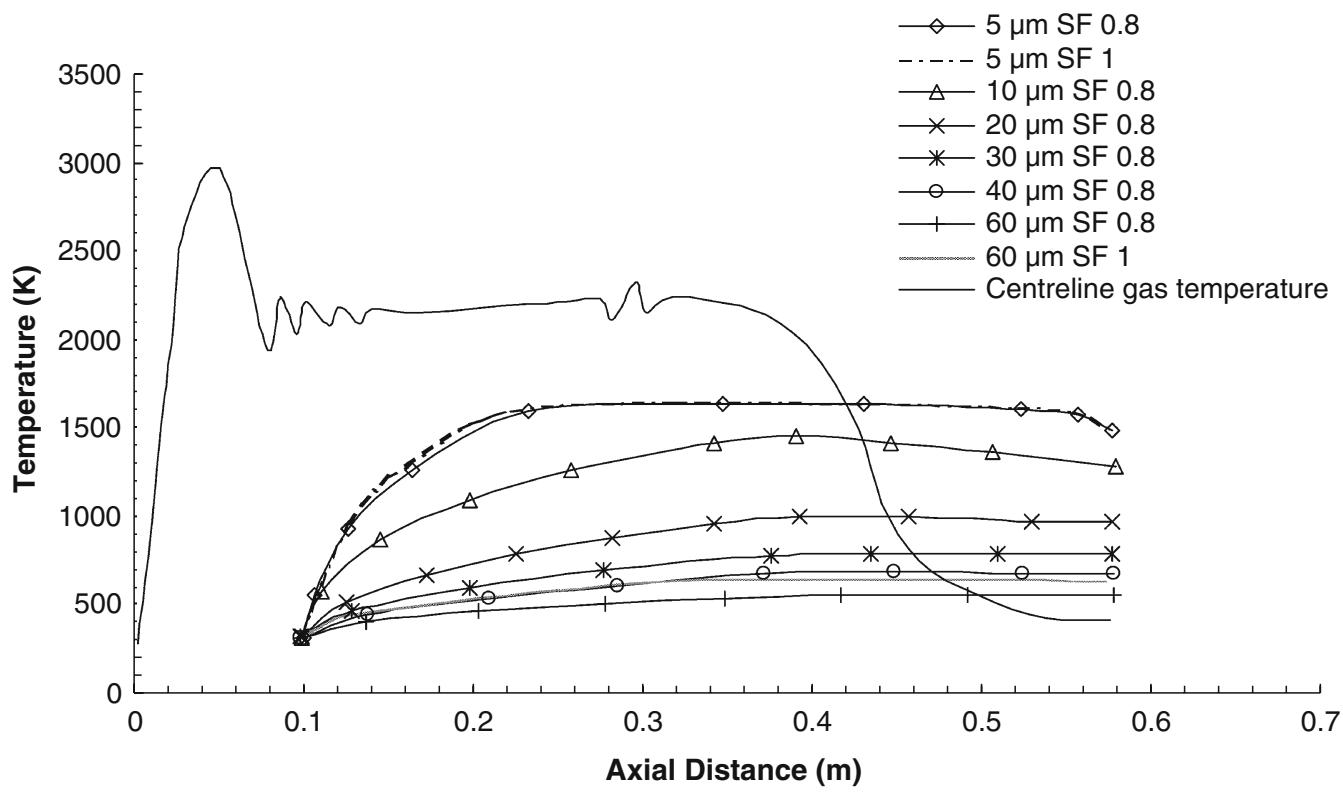

Fig. 9 Temperature evolutions for different size particles

the gun before stabilizing, and smaller particles are heated more rapidly than larger particles. Subsequently, as cold air penetrates deeply into the gas jet, the particle temperature starts to decline due to the rapid decrease of gas flow temperature. It is seen from Fig. 9 that only particles smaller than $5 \mu \mathrm{m}$ in diameter undergo melting and solidification, implying that most WC-Co powder particles sprayed with the liquid fuelled HVOF system never reach the molten state. The temperature evolution of $5 \mu \mathrm{m}$ particles shows that the rapid heating of particles comes to a stop when the particle surface temperature reaches the solidus temperature at $1580 \mathrm{~K}$. The surface temperature increases slowly as the solidus isothermal surface moves toward the center of the particle, and the particle never reaches the fully liquid state since its surface temperature does not rise quickly enough to reach the limit value. Prior to impact the particle surface reaches the solidus temperature again, the particle becomes solid instantaneously and its temperature declines further. Therefore, it is clear that the HVOF thermally sprayed WC-Co powder is mainly in solid state before impact on the substrate. By comparing the temperatures of 5 and $60 \mu \mathrm{m}$ particles at SF 1 and 0.8 in Fig. 9, it is apparent that the reduction in temperature is more substantial for highly nonspherical particles, due to their greater improved velocities and less dwell time inside the hot gas flow. 


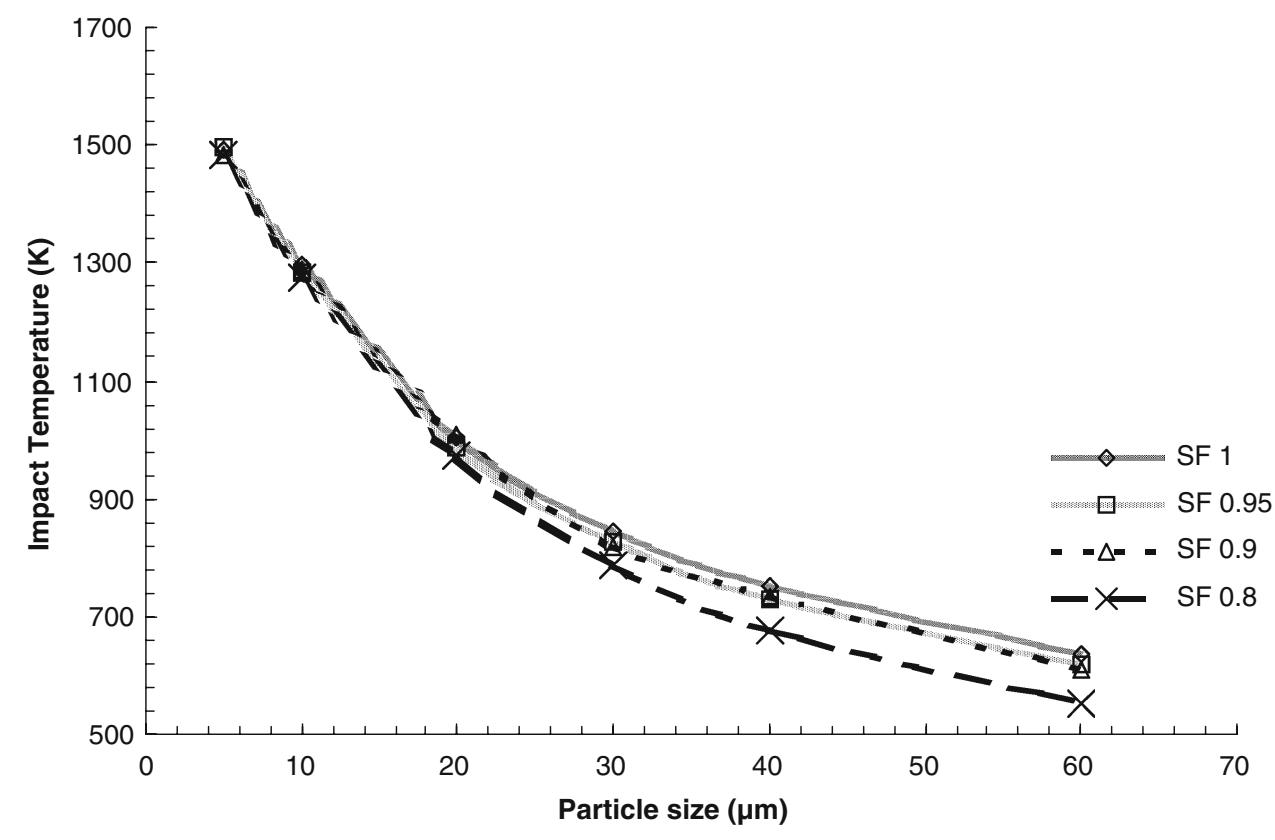

Fig. 10 Particle temperatures at impact

SF:1
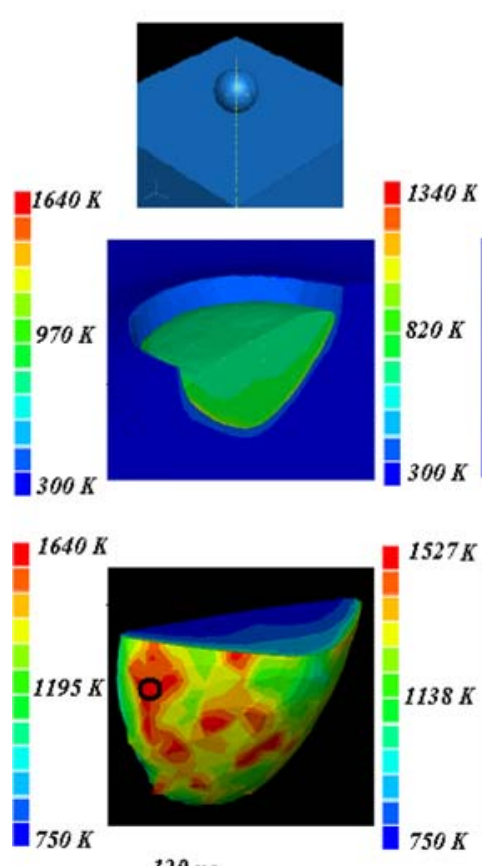

$130 n s$
SF:0.95

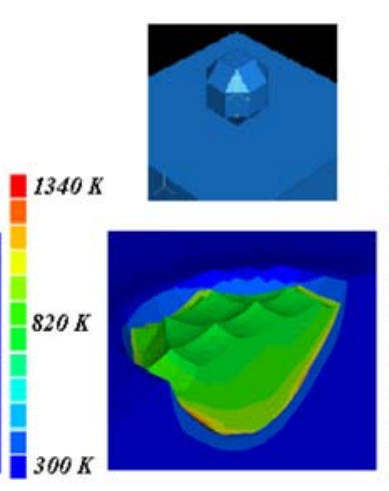

$\mathrm{SF}: 0.9$

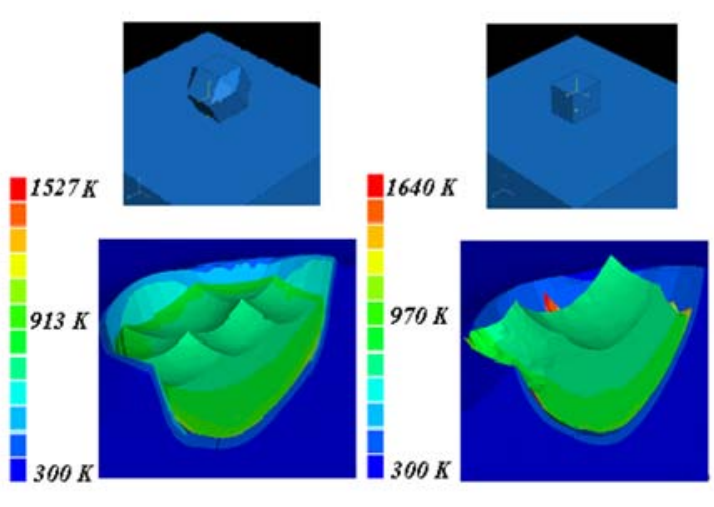

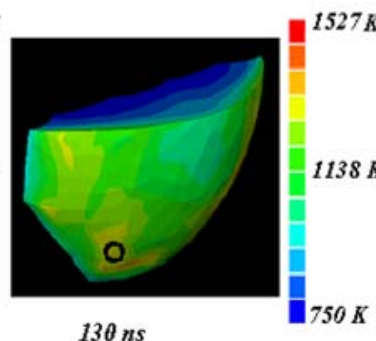
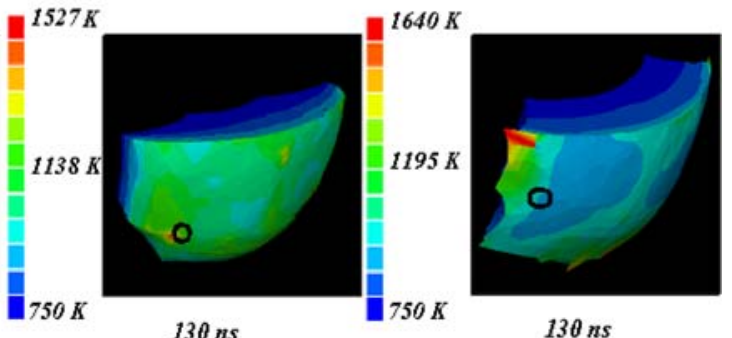

$130 n s$

Fig. 11 Temperature contours for different shape $40 \mu \mathrm{m}$ particles with impact temperature of $750 \mathrm{~K}$ and velocity $420 \mathrm{~m} / \mathrm{s}$ at $130 \mathrm{~ns}$ (Top: before impact; Middle: after impact; Bottom: interfacial contact surface)

\subsection{Particle Impingement}

3.2.1 Effect of Particle Morphology. The in-flight particle results show that nonspherical particles reach higher average velocities than the spherical powder at the same operation parameters due to higher drag coefficient for nonspherical particles. It is believed that the kinetic energy prior to impact is a key factor for strong adhesion. Purely based on the value of impact velocity, the nonspherical powder should have generated better coating from HVOF process. In fact particle morphology also influences the deformation rates during particle impingement. To examine such effect, the impingements from four $40 \mu \mathrm{m}$ particles 


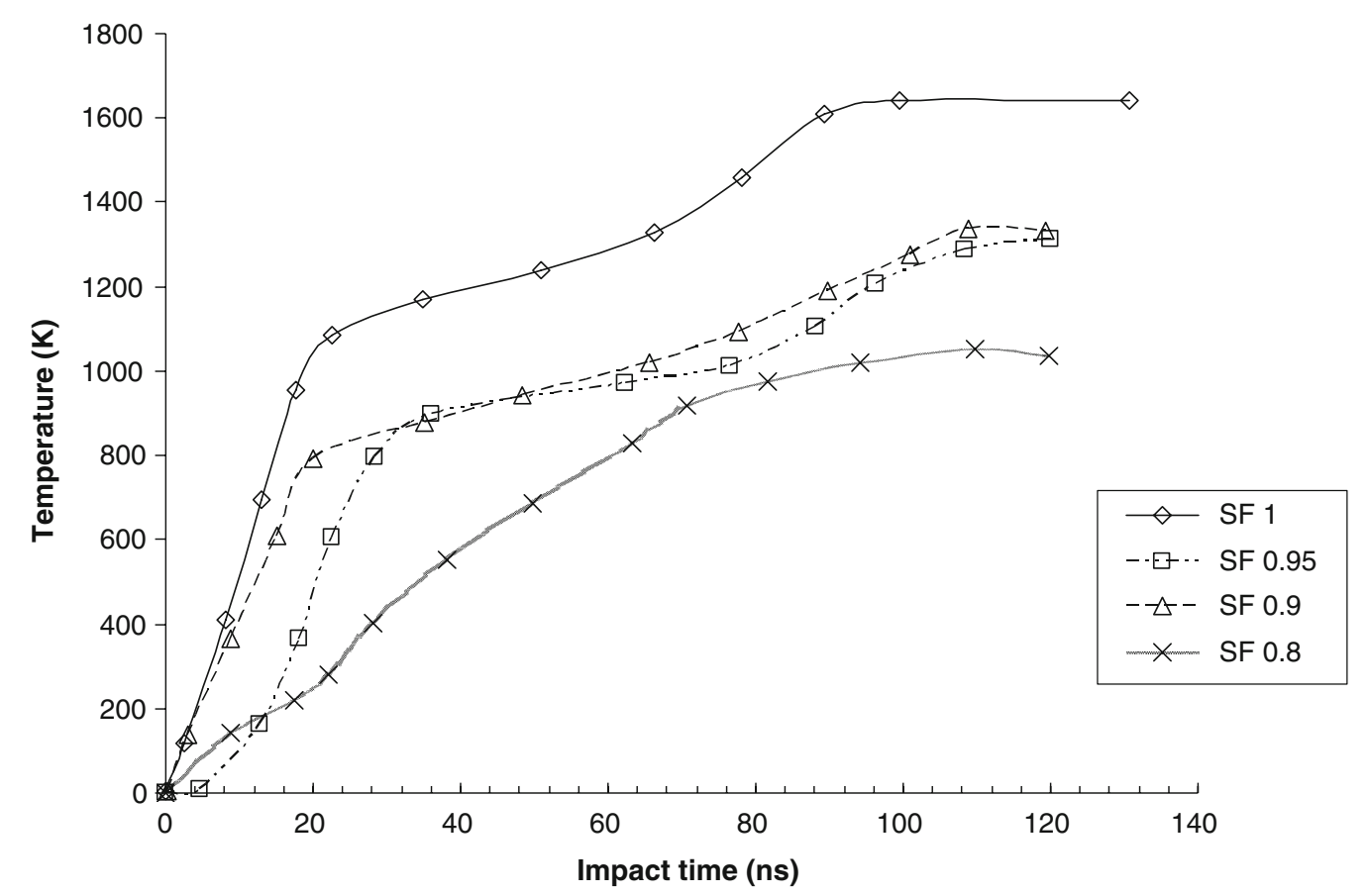

Fig. 12 Temperature developments during the course of impingement at the critical nodes for different shape particles

with different morphology are compared in Fig. 11. The particles are given the same impact parameters, i.e., velocity of $420 \mathrm{~m} / \mathrm{s}$ and temperature of $750 \mathrm{~K}$. The results show that all the particles create a crater on the substrate. The interfacial region between the particle and substrate has lower temperature as the SF of particle decreases. The resistance to the temperature build-up in the interfacial region is caused by the lower levels of plastic deformation at low SF. The decreased plastic deformation is attributed to the increased contacting area between the nonspherical particles and the substrate at impact which subsequently reduces flow stress concentration compared to the sphere particle. The results demonstrate that higher impact velocities are required for highly nonspherical particles such as SF 0.8 to achieve particle melting at the interfacial region which enables the formation of bonding required for mechanical interlocking of the particle-substrate.

For more quantitative comparison, a point in the maximum deformation area for each particle is selected as illustrated in the black circles in Fig. 11. The temperature developments during the course of impingement at those points are plotted in Fig. 12. It is apparent that the temperatures increase during the impingement, which results in more strain and deformation. The most substantial rise of temperature occurs at the initial stage of impingement (0-30 ns) where the kinetic energy is at the highest level. The temperature increase becomes steady between 30 and 80 ns. From then, a slightly more pronounced temperature rise is visible particularly for the spherical particle. This is due to the temperature-related softening effects in the particle. The curved surface of the spherical particle permits the kinetic energy to flow from the nearby nodes to the critical point and increase its internal energy. Such a temperature increase is less noticeable as the particle becomes less spherical, where the bumpy surface prohibits the inflow kinetic energy from the nearby nodes. The microstructure analysis of thermally sprayed coating (Ref 12) confirms the simulation results that spherical powder gives denser coating whereas the milled nonspherical powder does not exhibit the same extent of deformation and create more porous coatings.

3.2.2 Effect of Particle Orientation. The gas flow in HVOF spray processes are characterized by very high turbulence intensities, particularly in the supersonic jet region where the hot combusting gases are mixed with the ambient air. The velocity fluctuations in three-dimensional form have a direct influence on the motion of powder particles. In the case of nonspherical powder, the particles are more sensitive to flow fluctuations, therefore the particle orientation at the impact moment can be different for similar particles at the same operation conditions. It is interesting to know to what extent this impact orientation affects the bonding strength. Figure 13 shows the temperature contours of deformed particles having a SF of 0.8 for two different impingement orientations. The particle is impacting with a velocity of $420 \mathrm{~m} / \mathrm{s}$ and a temperature of $750 \mathrm{~K}$. The temperature distributions over the interfacial regions clearly show a temperature rise, which corresponds to high deformation when the contact area between the particle and substrate is decreased. The substantial influence of particle orientation at the impact implies another possible means to improve the deposition efficiency of coating by maneuvring the nonspherical particles into a desirable orientation.

3.2.3 Critical Impact Conditions. The above analysis is based on $40 \mu \mathrm{m}$ particle size. In reality, thermally sprayed powder is produced with a size distribution. It is necessary to know the critical impact velocities and temperatures for 

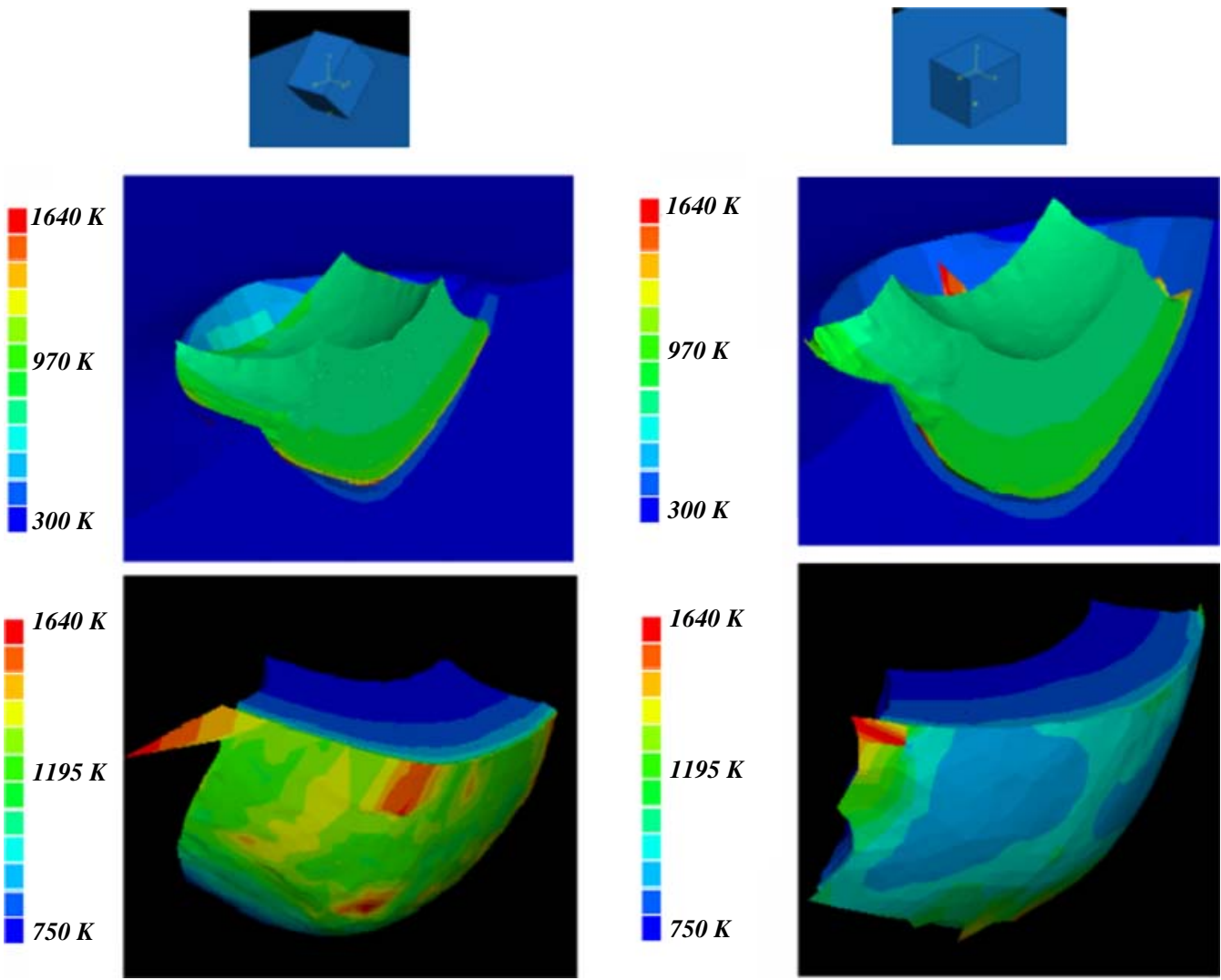

Fig. 13 Temperature contours of SF 0.8 particles with different orientation at impact (Top: before impact; Middle: after impact; Bottom: interfacial contact surface)

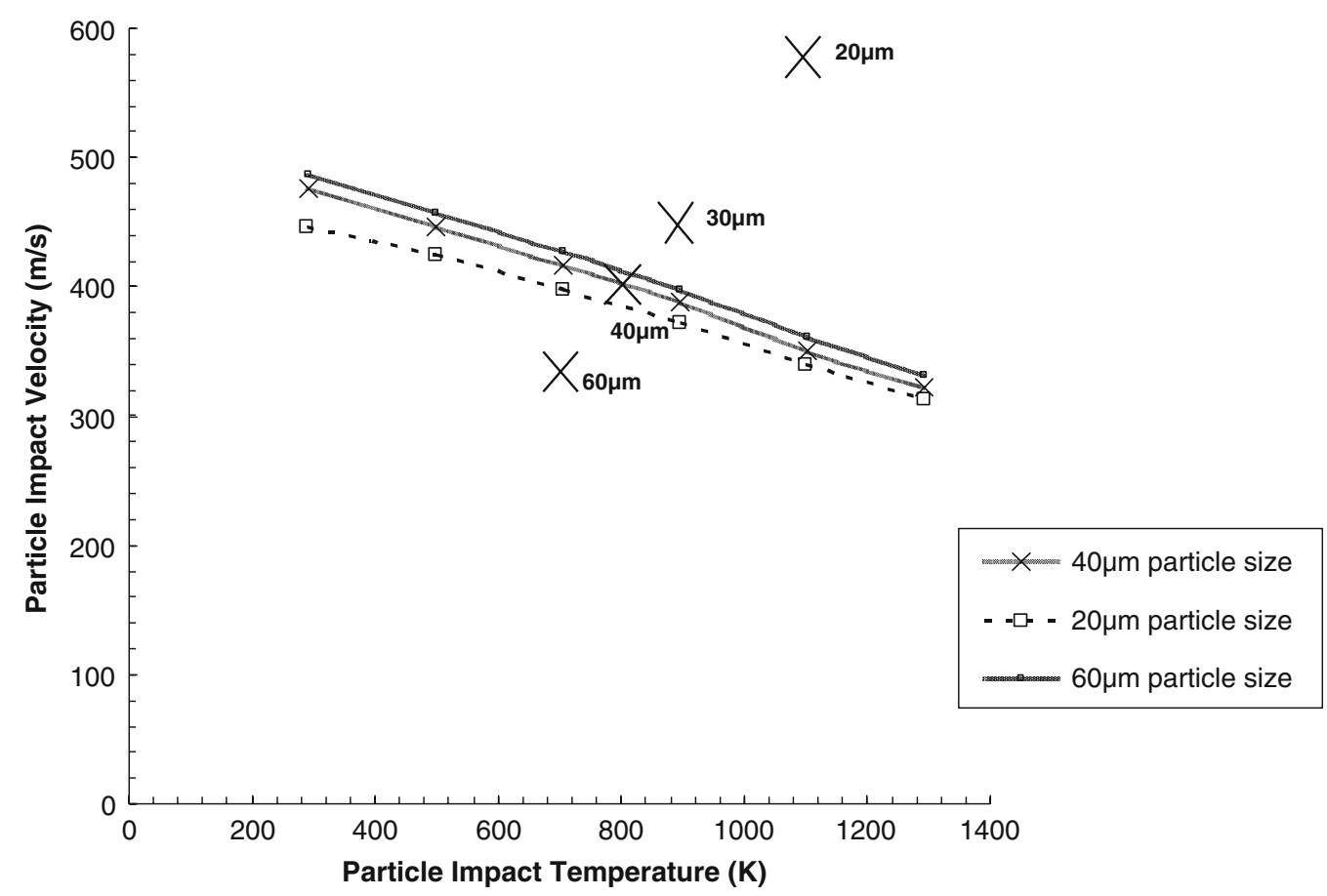

Fig. 14 Critical impact parameters for spherical particles 

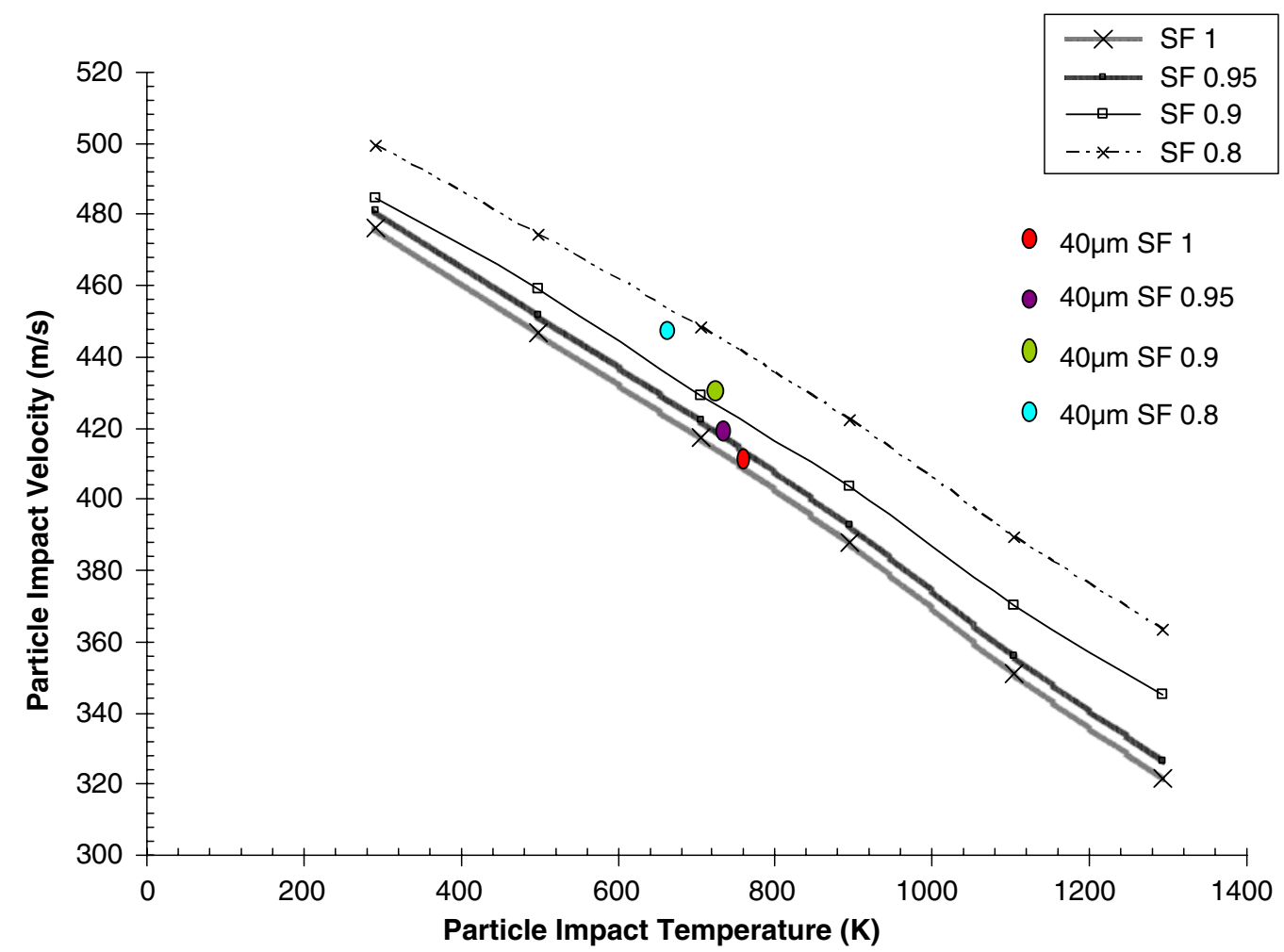

Fig. 15 Critical impact parameters for different shape $40 \mu \mathrm{m}$ particles

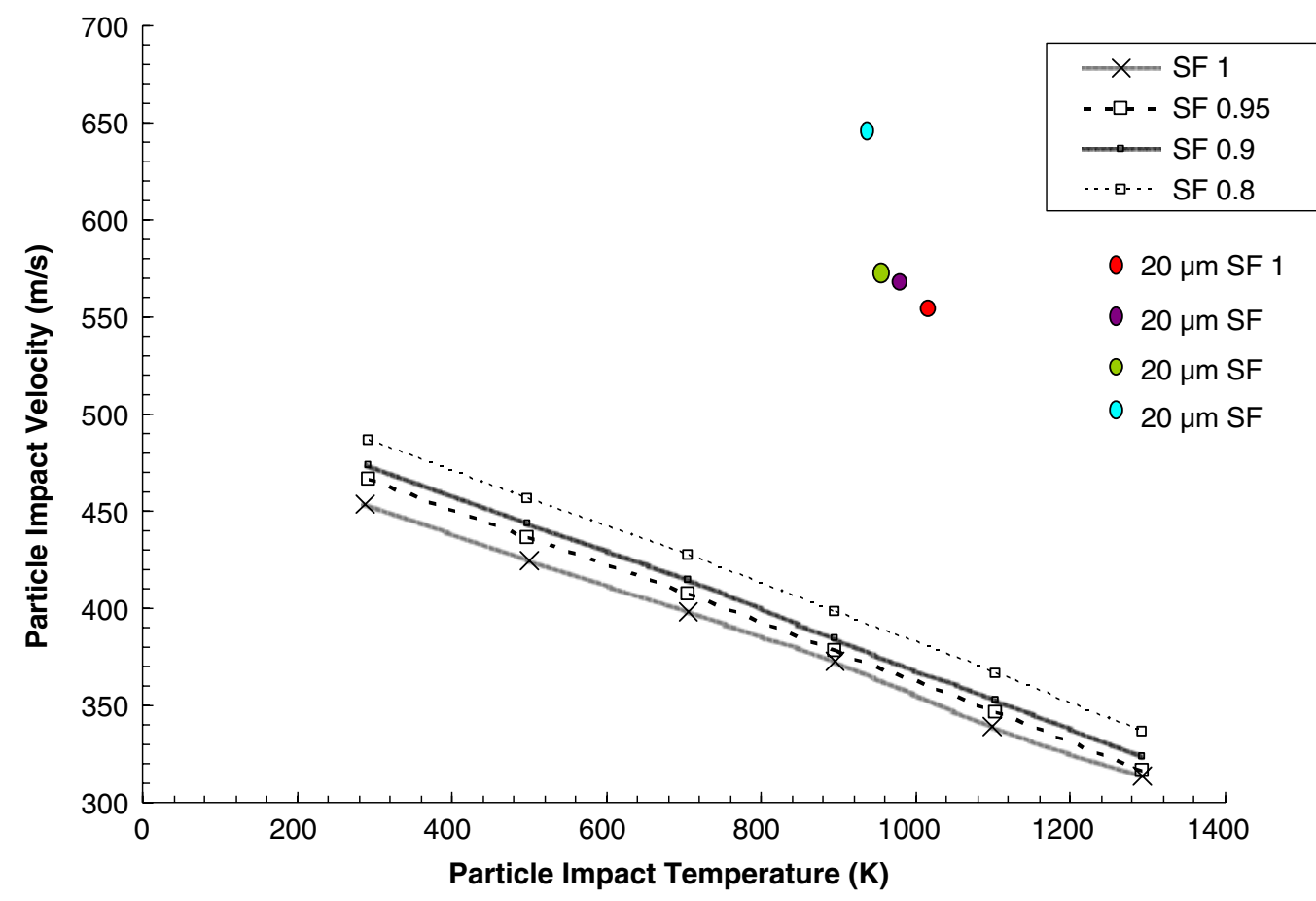

Fig. 16 Critical impact parameters for different shape $20 \mu \mathrm{m}$ particles

different particle size and morphology to obtain adequate bonding strengths. Figure 14 plots the critical velocity as a function of impact temperature for spherical powder with size 20,40, and $60 \mu \mathrm{m}$. The results indicate that a proportional increase of critical velocity is required as the particle becomes larger. The $\mathrm{X}$ points represent the 
particle impact velocities and temperatures obtained from the CFD models for in-flight particle dynamics. For the particles located above the lines, the impact temperature and velocity are adequate to ensure adequate bonding with the substrate. For the range of particles used, only powder sizes smaller than $40 \mu \mathrm{m}$ have enough kinetic and thermal energy to result in successful bonding.

To address the nonspherical particle deposition efficiency, Fig. 15 shows the critical velocity profiles for different $40 \mu \mathrm{m}$ particles. The color dots are the results taken from an in-flight particle simulation for HVOF process. When the SF is reduced from 1 to 0.9 , the increase in particle impact velocity gives a marginal improvement in bonding strength. However, for the particle with SF 0.8, the increased momentum output is not sufficient to overcome the lower plastic strain of the powder and generate deformation required for adequate bonding. When the particle size is reduced as shown in Fig. 16 for $20 \mu \mathrm{m}$ particles, the HVOF gun generates a very good momentum output for all the particles to exceed the critical impact parameters.

\section{Conclusions}

Computational models are developed to examine thermally sprayed nonspherical particles. The CFD method is employed for the in-flight particle dynamics while FEA approach is used for solid particle impact on substrates. A summary of conclusions are as follows:

- Nonspherical particles are accelerated to higher velocities with lower temperatures than spherical powders during HVOF coating.

- Nonspherical particles require more kinetic energy for good adhesion on the substrate. A $40 \mu \mathrm{m}$ particle with $\mathrm{SF}<0.8$ sprayed by the HVOF gun is not able to adequately bond with the substrate.

- The orientation of nonspherical particles at impact affects the plastic deformation rate in the interfacial region and consequently the bond strength, which gives more complexity for spraying nonspherical powder.

\section{References}

1. G.D. Power, E.B. Smith, T.J. Barber, and L.M. Chiapetta, Analysis of a Combustion (HVOF) Spray Deposition Gun, UTRC Report No. 91-8, UTRC, East Hartford, CT, 1991

2. E.B. Smith, G.D. Power, T.J. Barber, and L.M. Chiapetta, Application of Computational Fluid Dynamics to the HVOF Thermal Spray Gun, Thermal Spray: International Advances in Coatings Technology, C.C. Berndt, Ed., ASM International, Materials Park, OH, 1992, $805 \mathrm{p}$

3. W.L. Oberkampf and M. Talpallikar, Analysis of a High Velocity Oxygen-Fuel (HVOF) Thermal Spray Torch. Part 1. Numerical Formulation, J. Therm. Spray Technol., 1996, 5, p 53-61
4. W.L. Oberkampf and M. Talpallikar, Analysis of a High Velocity Oxygen-Fuel (HVOF) Thermal Spray Torch. Part 2. Computational Results, J. Therm. Spray Technol., 1996, 5, p 62-68

5. B. Hassan, W.L. Oberkampf, R.A. Neiser, and T.J. Roemer, Computational Fluid Dynamic Analysis of a High Velocity Oxygen-Fuel (HVOF) Thermal Spray Torch, Thermal Spray Science and Technology, C.C. Berndt, Ed., ASM International, Materials Park, OH, 1995, p 193-198

6. A.R. Lopez, B. Hassen, W.L. Oberkampf, R.A. Neiser, and T.J. Roemer, Computational Fluid Dynamics Analysis of a WireFeed, High-Velocity Oxygen Fuel (HVOF) Thermal Spray Torch, J. Therm. Spray Tech., 1998, 7, p 374-382

7. S. Gu, C.N. Eastwick, K.A. Simmons, and D.G. McCartney, Computational Fluid Dynamic Modelling of Gas Flow Characteristics in a High-Velocity Oxy-Fuel Thermal Spray System, J. Therm. Spray Tech., 2001, 10, p 461-469

8. D. Cheng, Q. Xu, G. Trapaga, and E.J. Lavernia, The Effect of Particle Size and Morphology on the In-Flight Behavior of Particles during High Velocity Oxy-Fuel (HVOF) Thermal Spraying, Metall. Mater. Trans. B, 2001, 32, p 525-535

9. M. Li, D. Shi, and P.D. Christofides, Modeling and Control of HVOF Thermal Spray Processing of WC-Co Coatings, Powder Technol., 2005, 156, p 177-194

10. M. Li and P.D. Christodes, Multi-scale Modeling and Analysis of an Industrial HVOF Thermal Spray Process, Chem. Eng. Sci., 2005, 60, p 3649-3669

11. D. Shi, M. Li, and P.D. Christofides, Diamond Jet Hybrid HVOF Thermal Spray: Rule-Based Modeling of Coating Microstructure, Ind. Eng. Chem. Res., 2004, 43, p 3653-3665

12. M. Li and P.D. Christofides, Computational Study of Particle In-Flight Behavior in the HVOF Thermal Spray Process, Chem. Eng. Sci., 2006, 61, p 6540-6552

13. S. Gu, D.G. McCartney, C.N. Eastwick, and K.A. Simmons, Numerical Modeling of In-Flight Characteristics of Inconel 625 Particles during High Velocity Oxy-Fuel Thermal Spraying, J. Therm. Spray Tech., 2004, 13, p 200-213

14. M. Pasandideh-Fard, S. Chandra, and J. Mostaghimi, Int. J. Heat Mass Trans., 2002, 45, p 2229

15. S. Kamnis and S. Gu, Numerical Modelling of Droplet Impingement, J. Phys. D Appl. Phys., 2005, 38, p 3664-3673

16. S. Kamnis, S. Gu, T.J. Lu, and C. Chen, Numerical Modelling of Sequential Droplet Impingements, J. Phys. D Appl. Phys., 2008, 41, $165303(7 \mathrm{p})$

17. W.Y. Li, C. Zhang, X.P. Guo, J.L. Xu, C.J. Li, H. Liao, C. Coddet, and K.A. Khor, Ti and Ti-6Al-4V Coatings by Cold Spraying and Microstructure Modification by Heat Treatment, Adv. Eng. Mater., 2007, 9, p 418-423

18. S. Kamnis and S. Gu, 3-D Modelling of Kerosene-Fuelled HVOF Thermal Spray Gun, Chem. Eng. Sci., 2006, 61, p 5427-5439

19. S. Kamnis and S. Gu, Numerical Modelling of Propane Combustion in a High Velocity Oxygen-Fuel Thermal Spray Gun, Chem. Eng. Process., 2006, 45, p 246-253

20. N. Zeoli, S. Gu, and S. Kamnis, Numerical Simulation of In-Flight Particle Oxidation During Thermal Spraying, Comput. Chem. Eng., 2008, 32, p 1661-1668

21. S. Kamnis, S. Gu, T.J. Lu, and C. Chen, Computational Simulation of Thermally Sprayed WC-Co Powder, Comput. Mater. Sci., 2008, 43, p 1172-1182

22. H. Assadi, F. Gartner, T. Stoltenhoff, and H. Kreye, Bonding Mechanism in Cold Gas Spraying, Acta Mater., 2003, 51, p 43794394

23. S. Gu and S. Kamnis, Numerical Modelling of In-Flight Particle Dynamics of Non-Spherical Powder, Surf. Coat. Technol., 2009, 203, p 3485-3490

24. B. Jodoina, L. Ajdelsztajnb, E. Sansoucya, A. Zúñigac, P. Richera, and E.J. Laverniab, Effect of Particle Size, Morphology, and Hardness on Cold Gas Dynamic Sprayed Aluminum Alloy Coatings, Surf. Coat. Technol., 2006, 201, p 3422-3429 